\title{
NAS TEIAS DA INTERMIDIALIDADE: O CARANDIRU DE VARELLA E O DE BABENCO
}

\section{IN THE WEB OF INTERMEDIALITY: VARELLA'S AND BABENCO'S CARANDIRU}

\author{
Norma de Siqueira Freitas
}

RESUMO: Reflexão sobre o processo de adaptação de obras da literatura, transmutadas para a linguagem cinematográfica. O objetivo é a análise do trânsito entre os textos: Estação Carandiru (EC), livro de Drauzio Varella e o filme Carandiru, de Hector Babenco. Analisaremos o deslocamento do signo verbal ao visual a partir dos pressupostos de Andrew, Bazin, Gardies, Genette e Stam. Em diálogo com as principais teorias do cinema, adaptação concebida, então, como recriação, porquanto mudança de veículos artísticos exigirá processo de transformação pertinente.

PALAVRAS-CHAVE: literatura, cinema, adaptação, linguagem.

ABSTRACT: This article is a reflection on the process of the adaptation of literary works by their transmutation into cinematic language. It intends to analyze the transit between two texts: Drauzio Varella's book Estação Carandiru (EC) and Hector Babenco's film Carandiru. The displacement from the verbal to the visual sign will be analyzed by way of the theories of Andrew, Bazin, Gardies, Genette and Stam. Following the main theories on cinema, adaptation is conceived as re-creation, since a change in artistic vehicles requires a pertinent transformation process.

KEYWORDS: literature, cinema, adaptation, language.

\footnotetext{
* Universidade Federal Fluminense. Doutora em Letras: Literatura Comparada (literatura / cinema), pela UFF. Niterói. Mestre em Literatura Brasileira pelo Centro de Ensino Superior de Juiz de Fora. normasfreitas@ hotmail.com.
} 



\section{INTRODUÇÃO}

É de conhecimento geral que, desde cedo, o jovem cinematógrafo sentiuse seduzido pela experiente literatura. Buscou apoio, na arte da palavra, para firmar-se como instrumento estético. Se, em seus primeiros momentos, o cinematógrafo constitui-se como novidade, passada a euforia inicial, tornou-se necessário regimentar o cinema como forma de não somente atrair a camada popular da sociedade como também conquistar um público mais sofisticado e exigente. Nesse empenho criou-se, na França, na primeira década do século XX, a Companhia de Filmes de Arte que se valia de textos literários para a produção de filmes narrativos cujo objetivo maior era uma "melhora em relação à qualidade precária" (GRONEMEYER, 1998: 36) daquele cinema mecânico que se traduzia apenas pelos recortes do real.

Assim, o cinema narrativo apresenta por si só uma intensa relação de proximidade com a literatura. Entretanto essa suposta similitude não se apresenta como valor referencial de cópia, pois que cada veículo, a seu modo, opera com marcadores textuais específicos e, por isso, configurase como recriação, isto é, como textos autônomos, o que faz com que as noções de cópia e original caiam por terra. 
Dentro desse pressuposto, levantaremos algumas particularidades sobre o processo de transposição entre o livro Estação Carandiru, do médicoescritor Drauzio Varella (1999) e o filme Carandiru, de Hector Babenco (2003), produção cinematográfica brasileira que transpõe para a tela do cinema a experiência vivida pelo médico, enquanto desenvolvia trabalho assistencial, no Complexo Penitenciário do Carandiru, presídio de São Paulo.

A tessitura de Varella, bem como a de Babenco, retira do criminoso o antigo glamour herdado dos filmes americanos, dissipando a imagem "robin-hoodiana" e hollywoodiana dos fora-da-lei. Os excluídos nas narrativas desses cárceres do fim do século vinte, e início do vinte e um, são homens comuns - de maioria pertencente à camada menos favorecida da população - envolvidos no mundo do crime, seja por motivos pessoais ou pela força das circunstâncias. De forma que, numa objetividade quase clínica, o corpo-prisão - assim como o corpo dos detentos - transforma-se em objeto literário. Organismos que, desenhados na folha de papel, acabam por se adensarem quando visualizados, concretamente, na moldura da tela: corpos controlados e doentes, viciados e brutalizados pelo mundo do crime e pelo ambiente contaminado da prisão.

\section{LINGUAGENS EM DESLOCAMENTO: DA PALAVRA À TELA}

A questão central dos estudos da adaptação gira em torno da diferença entre a apreensão das imagens verbais e das imagens visuais, sobre o "ver" na literatura e no cinema. A discussão estende-se, mais ainda, quando os espectadores, grosso modo, buscam total equivalência entre livro e filme. É fato que letra e imagem uniram-se, aos poucos, na história do cinema. Imagens do cinema mudo cederam lugar aos filmes sonoros, oportunizando o entrelaçamento de códigos, isto é, o enlace entre palavras e imagens concretas.

Ocorre que a reescrita fílmica - oriunda da leitura executada pelo cineasta (e sua equipe) - não raras vezes se distancia das imagens formadas na mente do leitor pela decodificação dos códigos verbais apresentados pela obra literária. E o resultado é a sensação de vazio experimentado por quem espera ver - na superfície da tela - o que, anteriormente, imaginara ao deslizar dos olhos sobre a página. E o espectador, então, recorre à indagação: por que o filme não corresponde, exatamente, às imagens formadas pela decifração dos signos verbais? 
Ora, durante a leitura de um livro nossa imaginação trabalha de tal modo que construímos nossas próprias representações. Montamos nossas personagens com a expressão de nossa imaginação. Vestimo-las, atribuímos a ela aspectos exteriores e interiores que, talvez, o escritor não tenha sequer pensado. Delineamos todo um mundo, um cenário em que nossas personas possam agir. Matizes são acrescentados por nós, enquanto leitores, às cores doadas pelo romancista e outros tons se sobrepõem à sua tessitura. Enfim, adornamos a trama à nossa semelhança.

Mas, eis que efeitos especiais do mundo do cinema bordam, mesmo que a partir da matriz literária, outra feição. Da leitura do cineasta, mediada e intermediada pelo olho-câmera, surgem imagens concretas que se fixam na superfície plana da tela. Na sala escura, usufruímos, agora, de corpos, ações e cenários concretizados, freneticamente, a nossos olhos. Intrigamo-nos e, em vários momentos, externamos: "é diferente", "não gostei", "o livro é melhor que o filme", ou "o filme é melhor" e assim por diante. Não é preciso muito para compreender o motivo da estranheza: fôramos excluídos, quase que totalmente, da obra. É certo que, vez ou outra, embora conduzidos pelo aparato cinematográfico, podemos andar, cautelosamente, por espaços e observar ações que se desenrolam diante de nosso olhar atento. Entretanto, como tudo no cinema é muito rápido - sendo o movimento sua razão de ser - nossa imaginação esbarra na cena seguinte e o tempo para reflexão fica para depois, para o momento em que se encerrem os créditos.

Sabemos que o discurso fílmico é criação autônoma e como tal não implica, necessariamente, que o espectador tenha executado leitura prévia da fonte literária. Observamos, entretanto, que espectadores - quando do contato anterior com o livro - estabelecem comparações entre as duas modalidades artísticas e que tais comparações esbarram, essencialmente, no princípio da fidelidade. Por que a frustração diante da constatação da diferença? Sempre será diferente. São artes distintas, veículos de comunicação também diversos. Condição de recepção igualmente outra. Não há como ser igual. E mesmo as supostas equivalências encerram em si o princípio da diferença: semelhança que se baseia na dessemelhança de meios.

A questão a respeito de uma pretensa equivalência entre filme/livro tem motivado calorosas discussões. Se, por uma lado, alguns poucos teóricos insistem na manutenção da fidelidade; uma maior parte assume postura mais flexível. No primeiro caso, podemos incluir André Bazin. Para o teórico, é possível haver "cruzamentos fecundos" entre as artes. Contudo quando os cruzamentos dizem respeito à adaptação - e ainda que o 
estudioso não a veja como "decalcomania" - acaba por apontar em direção à fidelidade, uma vez que para ele a "boa adaptação deve conseguir restituir o essencial ao texto e ao espírito" (1991: 96) e, com isso, insiste na questão das equivalências. Imbuído dessa ideia, acrescenta ser "errôneo apresentar a fidelidade como uma sujeição, necessariamente negativa, a leis estéticas", argumentando que "as diferentes estruturas estéticas requerem ainda mais imaginação por parte do cineasta que almeja realmente a semelhança " (ibidem: 94).

Todavia um outro grupo apresenta visão mais distendida sobre o exercício intermidial. Compondo esse plantel está Gérard Genette, crítico da Escola Francesa, que nomeia o processo de entrelaçamento de textos de "transtextualidade"; esta considerada como "tudo aquilo que coloca [um texto] em relação manifesta ou secreta com outros textos" (1982: 7). ${ }^{1} \mathrm{O}$ teórico chama o texto de partida como hipotexto (texto-origem) e o texto de chegada de hipertexto (cf. p. 7-12). Sugerindo o termo transmodalização (cf. p. 324-330) como processo que consiste em modificação do modo de representação, salienta que a transposição de um texto num outro pode ser considerada uma recriação, já que certos ajustes tornam-se necessários.

Dudley Andrew (2000) vai mais além. Para ele a noção mais ampla do processo de adaptação muito tem em comum com a teoria da interpretação, pois, num sentido mais amplo, a adaptação é a apropriação do significado a partir de um texto anterior (2000: 29). Vale salientar que, como arte autônoma, o cinema não pode exigir que o espectador só compreenda o filme a partir da leitura da narrativa literária. Ao contrário, mesmo um filme adaptado pode, ele mesmo, ser percebido em sua inteireza por seus mecanismos narrativos de linguagem, por suas marcas discursivas. Andrew considera, ainda, que "a adaptação delimita a representação ao insistir no status cultural do modelo" (2000: 29). Sustém a importância de situá-la sempre dentro de outro sistema de signos, já que opera com combinações de diferentes sistemas que vão ao encontro de nossas associações. $\mathrm{O}$ teórico postula que "cada trabalho de arte é um construto de elementos construídos a partir de um uso tradicional de um sistema". E acrescenta que "signos verbais e cinematográficos compartilham um destino comum: serem condenados à conotação"; porquanto, na ficção, "cada significante identifica um significado, mas também explicita uma cadeia de reações para outras relações". (ibidem: 33).

\footnotetext{
${ }^{1}$ As traduções de citação neste ensaio são de minha autoria.
} 
Importa, então, deixarmos de lado as "pseudoequivalências", termo cunhado por André Gardies (1992), para concentrarmos atenção nas "operações narratológicas" executadas pelo cineasta, quando de sua releitura do texto-base. Nesse caso, o texto literário se comportaria, apenas, como um reservatório de instruções, a partir do qual o diretor efetuaria escolhas, consideradas por ele adequadas ao meio de expressão e à forma de recepção, uma vez que, no trânsito entre sistemas semióticos distintos, há necessidade de levarmos em conta a ocorrência de dois sujeitos-receptores distintos (o do livro e o do filme), o que implicará transformações narrativas, no mais das vezes bastante significativas (cf. 1992: 66). As adaptações, portanto, funcionariam como leituras críticas do texto matriz, entretanto não subordinadas a ele, já que consideradas como obra original, isto é, como novo texto.

\section{ENTRE GRADES, LETRAS E IMAGENS: O CARANDIRU EM CARTAZ}

Habituado a retratar situações de exclusão, crime e desigualdade, o diretor de Lúcio Flávio, o passageiro da agonia (1977) e Pixote, a lei do mais fraco (1980) teve uma razão a mais para filmar a história do Dr. Varella. De uma relação médico/paciente, o cineasta Hector Babenco viu nascer o livro Estação Carandiru e, mesmo sem saber que um dia o filmaria, participava de conversas nas quais o médico discorria sobre sua experiência no Complexo Penitenciário e a escritura de suas experiências junto aos detentos.

Para o cineasta, recriar o livro de Drauzio Varella era mais que um desafio, além do mais, segundo Daniel Piza, a dificuldade dobrava quando se tratava de montar uma produção "à altura de um best-seller que, com mais de três anos na lista dos mais vendidos, superou 1 milhão de exemplares" (2003). E o artesão das imagens não mediu esforços para montar o seu Carandiru, um investimento ousado que demandou tempo, dinheiro e laboratório, já que os artistas, para entrarem no "clima da prisão", ficaram confinados em sombrias celas onde, antes do massacre, restavam, de fato, os prisioneiros da penitenciária.

Ora, se, nos relatos de Varella, o presídio abrigava mais de 7200 presos; o complexo penitenciário reuniu, no enunciado fílmico, mais de 8000 detentos (personagens), tendo mobilizado, "do roteiro pronto à primeira cópia e lançamento, três anos de trabalho". O trabalho de equipe contou com "mais de duzentos e cinquenta profissionais". No elenco atuaram "vinte e seis atores principais, cento e vinte secundários, além de oito mil diárias de figurantes". A produção contabilizou cerca de "três meses de intenso 
trabalho de ensaio" qualificando "os cento e quarenta e seis atores de maior ou menor destaque no filme" (BABENCO, 2003a).

A montagem sofisticada da produção, segundo Hector Babenco, levou ao consumo de "seiscentas latas de negativo, o correspondente a setenta mil metros de imagens impressas". No geral, houve a utilização de duas câmeras de $35 \mathrm{~mm}$, ressalvando-se que, em sequências especiais, optou-se por filmar "com até cinco câmeras". Só na montagem das imagens foram gastos oito meses de intenso trabalho, mais quatro para montagem do som, cuja mixagem foi feita em Nova York (ibidem). Todo esse investimento deixa claro que um filme, como produto da indústria cinematográfica, necessita gerar capital: lucro que se traduz em sucesso de bilheteria.

Embora haja a preocupação estética, certo é que violência e marginalidade transformam-se em espetáculo, ficando a crítica social, apenas, no subentendido das imagens sangrentas, nos silêncios e nos sombrios corredores da prisão. Segundo o próprio Babenco:

Eu não diria que optei por despolitizar. Eu optei por não politizar, mas acho que não está despolitizado. A organização das imagens foi feita de tal forma que eu acho que fica claro quem fez o quê, como, onde e contra quem. O político está no não-verbalizado. Está no mostrado. [...] Eu poderia ter entrevistado [...] pessoas, entrevistado o Fleury e colocado isso no filme. Vira uma bomba! Poderia ter tranqüilamente anexado essas informações documentadas dentro de um corpo ficcional. Optei por não fazê-lo [...] E também não estou aqui para ficar denunciando [...] Sou um artesão modesto que adaptou um livro que está dando certo. Estou tentando contar uma história para entreter o público. Acho que é o filme mais popular que eu já fiz (apud CARVALHO, 2003: 108-110).

O cineasta argentino está habituado a amealhar sucessos. E, na maioria das vezes, o sucesso atrela-se à literatura, posto que o artista mantém relação carinhosa com palavras e livros. É considerável, em sua filmografia, a lista de adaptações cinematográficas concebidas a partir de matrizes literárias. Dessa relação, surgiram, pelo menos, seis dos seus oito longas-metragens, dentre eles, Pixote, a lei do mais fraco, cujo hipotexto é o romance Infância dos mortos, de José Louzeiro. Sobre essa relação forte com a literatura, em entrevista concedida a Alexandre Agabiti Fernandez, Babenco justifica:

A imagem sem a palavra não funciona para mim, não consigo concebê-la. Não sei relacionar-me com a imagem independente do texto. A imagem é a forma que tenho de usar a palavra. Âs vezes, durante a montagem, deixo de cortar um 
trecho de uma cena só por causa de um pequeno diálogo, que para mim é como um haicai, é um deleite. Os livros me inspiram a fazer filmes (FERNANDEZ, 2003).

Ciente de seu ofício e de seu fazer criativo, logo no início dos créditos do Carandiru, o cineasta, sob a legenda de "baseado em", deixa claro que não pretendeu a busca por fidelidade, o que acaba por resultar um trabalho com maior liberdade de expressão. Em sua releitura, o diretor-roteirista fundiu elementos transpostos dos relatos do médico-escritor, mesclou episódios e personagens, visando à maior plasticidade do tecido fílmico. Dudley Andrew salienta que, embora consideremos o texto cinematográfico em sua autonomia, há maior compromisso do cineasta com equivalências quando o filme é dado, claramente, como adaptação, enquanto para os "inspirados por ou derivados" a expectativa é somente que mantenham alguma referência com a fonte (2000: 28). E este parece ser o caso do Carandiru fílmico.

Em relação à questão de uma pretensa fidelidade à matriz literária, o próprio autor do livro, em depoimento gravado em DVD duplo, afirma que "a história foi modificada" e que Babenco, ao efetuar a transmutação, acabou por criar outro texto, outro presídio e muitas outras personagens porque, segundo nos informa o autor-narrador e também personagem: "Aquilo, na verdade, não é história de ninguém e nem sou eu também" (VARELLA, 2003). Assim, o ator que representou o Dr. Drauzio, no filme, não reproduz, de fato, a pessoa real do profissional que prestava serviço de assistência aos detentos. Efetivamente, a personagem é a construção ficcional de um médico que atuava no restrito espaço cenográfico da tela do cinema.

De acordo com a avaliação de Pedro Butcher, "o personagem com menos credibilidade é o único que não pertence ao universo da prisão, o narrador da história, interpretado por Luís Vasconcelos" (2003), o que é compreensível, pois não experimenta as mesmas dores, não divide o espaço do cárcere, apenas observa. E mesmo que tente aproximar-se continua a anos-luz de distância, destoante e dissonante da realidade de crueza e violência.

Mesmo no livro, o médico, como observador, situa-se em posição secundária, delegando aos presos a suposta veracidade dos fatos. No movimento pendular da narrativa varelliana e nos relatos que interrompem a voz do narrador, corpos diversos plenos de histórias compõem a galeria de miseráveis e desgarrados da Casa de Detenção. Se, no tecido literário, os flashbacks das versões dos presidiários são em maior número, num 
entrecortar e entrelaçar com a voz do autor-narrador; na leitura fílmica, no entanto, tal recurso serve a outra finalidade, a de inter-relacionar presente e passado, vida fora e dentro do cárcere, apresentando-se, algumas vezes, condensado às vozes dos apenados. Nas páginas finais do livro, o autor confessa ter somente ouvido os presos: posição ratificada por Babenco. Entretanto, nem por isso, é a tessitura de Babenco equivalente à de Varella, ao contrário, ambas são apenas versões de uma história de vida e morte, num Complexo Penitenciário chamado Carandiru.

O diretor objetivou transportar para o espaço bidimensional da tela a atmosfera borbulhante de uma ambiência na qual uma multidão de homens confinados teima em sobreviver. Ainda que Babenco afirme não ter pretendido fazer do filme um "documentário, docudrama ou politização exacerbada" (MUANIS, 2005: 61), tendo - assumidamente - declarado o propósito da ficção, fica, para nós, bastante difusa a linha fronteiriça entre os gêneros, já que, de fato, a reconstrução ficcional se apoia em fatos reais. O filme - como encenação desses fatos e pela utilização de ferramentas dramáticas - aponta na direção do chamado docudrama. É inegável que a opção por efetuar a filmagem, em grande parte, nas instalações do Complexo Penitenciário do Carandiru evidencia, em certa medida, a aproximação com o documentário, reforçando uma vez mais o entrelaçamento intermidial.

A narrativa de Babenco, de acordo com Clóvis Bueno (2003), buscava criar em cima do que era, na realidade, o Carandiru de Varella. No entanto sabemos que nunca haverá uma justa equivalência, uma vez que os códigos pertencem a linguagens bastante específicas. Se, na literatura, a palavra constitui-se como signo essencial, o cinema se coloca sob a égide da imagem. Entretanto, como arte múltipla, lança mão de códigos pertencentes a diversas outras artes.

No filme de Babenco, cada cela e cada corredor montam um universo diversificado. No cenário-presídio, qualquer desenho e cada gravura, ao serem estampados nas paredes, assumiam um caráter de depoimento, como se uma "história pictórica" fosse delineada por meio de cores e símbolos. Nomeados por Metz como "extracinematográficos" (1980: 133), esses códigos servem, em Carandiru, segundo nos informa Bueno, para estabelecer a diferença existente entre as alas, uma vez que um pavilhão configurava-se como um espaço peculiar e único, onde personagens diversas viviam conflitos específicos.

Como o presídio em si é a grande personagem da história, a montagem da ambiência fílmica ajuda também a compor as personagens cinematográficas. Parece possível afirmar, por exemplo, que a cela colorida 
de Majestade, personagem fílmica, traduza o perfil do detento sempre sorridente. As cores vivas, aliadas ao símbolo do Corinthians, juntamente com o do Gavião da Fiel, ajudam a tecer o retrato do amante bon vivant, marido de duas mulheres, não deixando dúvidas sobre o aspecto sedutor de Josué, o Majestade, um protagonista resultante da fusão de personagens no relato do médico-escritor.

O processo de fusão/condensação é prática comum na transposição dos signos verbais para os signos visuais. Cineastas como Truffaut, John Ford e Godard lançaram mão do processo. Em Contempt (1963), por exemplo, Godard adiciona a personagem Francesca na função de tradutora; já em Vinhas da Ira (produção americana de 1940, uma adaptação do romance de Steinbeck), o cineasta John Ford efetua um tipo de condensação de famílias. Dentro desse mesmo procedimento, as amantes femininas de Jules e Jim (França, 1962), transcodificadas do romance de Henri Pierre Roché, são condensadas em Catherine, personagem singular da adaptação do cineasta francês François Truffaut. (cf. STAM, 2000: 71).

Embora as personagens da cena cinematográfica apareçam transmutadas, o evento remete aos relatos de sua matriz literária. Dentro dessas "pseudoequivalências", anunciadas por Gardies (1998), podemos destacar ainda mais uma vez a tessitura das personagens cinematográficas: Deusdete e Zico. O último parece remeter a Mané, e ao mesmo tempo, ao bandido Zico da Vila Guarani, personagens que figuram no livro.

Um outro deslocamento decorre da fusão Zico/Ronaldo. Transtornado pelo uso excessivo da droga, o prisioneiro delira e, numa atitude de total esquizofrenia, ouve vozes e vê fantasmas a persegui-lo e a esconder-se sob as camas da cela. No livro, essa "paranoia" era vivida por Ronaldo, assaltante "pai de quatro filhos" que dizia ter "medo de abaixar" e deparar-se com alguém (EC: 132); enquanto, na tela, tal experiência é conferida a Zico.

Outras disjunções podem ser detectadas na relação livro-fonte e hipertexto fílmico. A primeira diz respeito à montagem da personagem do relato de Varella (Veronique) e o deslocamento efetuado pela equipe de filmagem (Lady Di). No filme, a personagem mantém um relacionamento amoroso com o detento-enfermeiro "Sem-Chance". A construção do par romântico constitui-se como uma subversão importante em relação ao livro. A fusão Rodrigo Santoro/Lady Di confere uma atmosfera talvez grotesca, na qual se mesclam humor e melodrama, levando o espectador a uma atitude que transita entre riso e deboche, entre sarcasmo e simpatia, enfim, entre atração e repulsa. 
O aproveitamento do ator televisivo, ídolo prestigiando pela TV, parece aproximar-se, como declara Daniel Caetano, de "nossa versão tupiniquim do star system hollywoodiano" (2005: 17). Se, no auge do cinema americano, em technicolor e cinemascope, beleza e juventude dos ídolos garantiam o sucesso do filme, nas produções contemporâneas, o florescimento das estrelas transforma-se e, de certa forma, desglamoriza-se, porquanto fruto, em sua maioria, da mídia de maior penetração. Segundo o articulista, em geral, a "aproximação do cinema com os ídolos da massa" (CAETANO, 2005: 17) aponta para uma estratégia comercial, que visa, muita vez, mascarar a debilidade de algumas narrativas, garantindo, desse modo, o sucesso do filme.

Num contínuo processo intertextual, Babenco aproveita-se de atores e atrizes de suas produções anteriores. A participação da atriz Maria Luíza Mendonça comprova isso. A encantadora Ana, de Coração iluminado (1998), transforma-se na impertigada Dalva, em Carandiru. Se, em Coração iluminado, a atuação da atriz resta apagada - pois o filme não chega a convencer o grande público -, atuando na trama de violência e morte e interpretando Dalva, Maria Luíza Mendonça destaca-se. Talvez porque subjaza, em seu desempenho, o picante jogo de sedução e disputa amorosa que, de certo modo, adiciona tempero ao filme.

Se, em Pixote, o cineasta mostra o universo de violência e carência - experienciado pelos menores infratores -; em Carandiru, talvez, vise denunciar o tipo de futuro a que aqueles meninos, agora então adultos, foram sentenciados. É como se o Carandiru, enquanto prisão, fosse o destino, determinado por Sísifo, daqueles menores abandonados pelo Brasil.

No processo de releitura, Hector Babenco deixa evidente que escolhas, associações e apropriações direcionaram seu fazer artístico. Se, como nos aponta Robert Stam (cf. 2000: 72), em Tom Jones, uma simples referência ao gosto pela caça serviu de pretexto para Tony Richardson montar sua espetacular caçada à raposa, aqui, no filme Carandiru, a simples menção à palavra balão, grafada no livro de Varella (EC: 225), estimulou a imaginação do cineasta na recriação de eventos que serviriam de suporte à identificação, posto que traduzem, em certa medida, os anseios de liberdade de todo ser humano. Esta estratégia de montagem em que balões são lançados ao ar, por Seu Chico, personagem fílmica, no entanto, parece propor uma visão edulcorada e paternalista do detento idoso, saudoso da família, buscando, talvez, certa aproximação da ótica apresentada nos relatos de Varella.

$\mathrm{Na}$ tessitura de realismo e crueza a se desenrolar no enquadramento da tela, conexões e deslocamentos, fusões e adições são observáveis. Ora, não 
podemos desconsiderar o fato de que são veículos distintos que trabalham com exigências de linguagem igualmente diferentes. $\mathrm{O}$ cinema, enquanto "arte impura" na classificação de Bazin (1991), vai dispor, a princípio, de signos visuais, aos quais se amalgamarão, como já dissemos, outras convenções como cores e sons. Em Carandiru, por exemplo, o vermelhosangue das cenas de violência extremada e os contrastes entre escuro e claro apontam para um universo tenso da vida criminosa. Os desenhos e asfotos, na elaboração da ambiência prisional, propõem de certa forma a humanização do presidiário e os sons - em especial a trilha sonora de Abujamra - são um acréscimo que compartilha coerentemente da tragicidade do tema. Então, todo esse entrelaçar de códigos cinematográficos e extracinematográficos (reiterando Christian Metz, 1980) justificam, uma vez mais, que cinema e literatura podem permutar serviços, mas são artes operando de maneira diversa e original.

O massacre já enormemente difundido pela mídia e também descrito pelo autor-narrador do livro, no capítulo de nome "O ataque" (EC: 286), faz parte da tessitura fílmica. Muitas leituras podem ser feitas a partir da prisão em chamas e das sucessivas cenas de matança, covardia e crueldade. Através do movimento do olho-câmera que ora afasta, ora aproxima pessoas e objetos, foi criada uma ambiência que dá o tom do filme, pois, "ao contrário da vida real, o cinema permite soluções de continuidade no espaço e no tempo. A montagem é a operação que consiste em ligar planos de situações que ocorrem em espaço e tempos diferentes" (ARNHEIM, [1960]: 95). E a montagem dessa sequência é bastante expressiva.

O episódio cinematográfico em que um cão policial passeia entre cadáveres embebidos no vermelho líquido viscoso, nas sombrias galerias do Carandiru, prende a atenção do espectador que, antes concentrado no intenso tiroteio, tem a respiração ainda presa. O contraste entre o ruído dos tiros, dos gritos e dos sons plangentes da trilha sonora - classificada de "não-diegética", isto é, ouvida somente por quem está sentado na poltrona da sala de cinema (MÁXIMO, 2003: 78) - incomoda o espectador, deixando-o com a sensação de um grito preso na garganta.

$\mathrm{Na}$ conhecida sequência da cena de extrema violência, a coreografia executada por policiais, o passeio do cão entre rios de sangue, a música de fundo são acréscimos, em que certa "licença poética" ajuda a compor a teia da ficção de Babenco. Ainda antes dos créditos de Carandiru, o somlâmina dos instrumentos indicia a tensão da narrativa de violência e morte. Informa ao espectador, por meio de tons sonoros, o tema da história. Coloca-o em vigília. 
À semelhança de Psicose (1960) de Alfred Hitchcock, quando o som tenta "descrever o que a imagem" mostra, ajudando, desse modo, o "diretor a contar a sua história" (ibidem: 11) e o espectador arrepiar-se com ela; também, em Carandiru, o tratamento dado à melodia pelo músico André Abujamra nos impõe certa tensão, obrigando-nos a perceber, desde a abertura do filme, $\mathrm{o}$ acontecimento terrível: a matança de aproximadamente uma centena de presos.

Ora, se os guinchos de violino sob a batuta de Herrmann, em Psicose, são capazes de levar o espectador a sentir os golpes desferidos pela mão que apunhala Marion na banheira; o som metálico e cortante da trilha sonora de Carandiru toca fundo o público, levando-o igualmente a "mais que ver, sentir" (ibidem: 11-12). Se os acordes pontuais do início da narrativa fílmica açulam os sentidos e, ainda, a imaginação do espectador, colocando-o em alerta; no momento de maior tensão, isto é, na sequência do massacre, cada nota funciona como se fossem desferidos golpes perfurantes no peito do espectador.

Essas angustiantes notas musicais ajudam a montar o universo do Carandiru, não, de fato, daquele real presídio, mas do outro construído pelo gênio criador do cineasta argentino em parceria com o talento do compositor brasileiro. De forma que os gritos metálicos, produzidos pelos instrumentos musicais, encaixam-se "com o macabro humor da cena" (ibidem: 15), acabando por ferir mais a consciência que os ouvidos do espectador ávido por histórias sangrentas.

Numa atmosfera na qual a música apenas soluça diante da brutal violência, instala-se o oco, a ausência de humanidade sugerida pelos silêncios da voz humana e pelas pausas na trilha sonora. O silêncio dos espaços não preenchidos, percebidos entre acordes intercalados, acaba adquirindo significância peculiar, pois, ao contrário do senso comum de que o silêncio é o vazio, as pausas - executadas entre uma nota e outra - estabelecem um interessante "jogo de presença e ausência" entre os elementos sonoros (COSTA, 2004: 111). O plano que destaca o cão a caminhar sobre o rio de sangue marca - em sua alternância com os gemidos da voz metálica e a total ausência de ruídos - toda a perplexidade diante do paradoxo vida e morte, força e castigo, coerção e liberdade.

A cena prossegue e, no corredor banhado de sangue, a câmera destaca um cão a deparar-se, frontalmente, com um minúsculo gato, conotando confronto desigual entre os oponentes. No vagar, o cão parece se alimentar da desgraça, ao mesmo tempo, estando alheio a tudo; como se a função da força e do poder fosse somente contabilizar perdas de forma irracional, 
desigual e banal. Na estrutura dessa parte do filme, os momentos de silêncio vão sendo demarcados pela alternância com sequências barulhentas. Em especial, na sequência que trata do massacre, sequências ruidosas se interpolam com as de apenas sons musicais entrecortados de pausas significativas.

Sabemos que o silêncio significa e o mundo acadêmico tem se debruçado sobre essa questão. A partir do ensaio "The Voice of Silence", do pesquisador Martin Rubin, Fernando Costa (em coro com o estudioso norte-americano) admite haver um quarto discurso sonoro: o "discurso do silêncio" (2004: 109), a que se somam outros três discursos: o da voz, o da música e o dos ruídos de forma geral. De fato, o silêncio só existe em oposição ao ruído e o diretor de Carandiru bem o demarca. Entre tiros de metralhadora, gritos desesperados, sons das brutas botas da polícia militar e da correria desenfreada dos detentos pelas escadas e corredores e, ainda, entre os quadros com depoimentos das personagens a respeito do acontecimento, o cineasta intercala, habilmente, a contundente trilha sonora com suas expressivas pausas. Recurso a constituir um deslocamento significativo em relação às supostas equivalências entre livro e filme, ratificando, mais uma vez, a tese de que veículos diferentes vão exigir linguagens distintas.

Portanto, a adição dos sons musicais audíveis (inexistente na tessitura literária) constitui uma disjunção especial e peculiar na comparação entre as obras, confirmando, sobremaneira, a intermidialidade entre as modalidades artísticas, em análise, neste artigo.

\section{CONSIDERAÇÕES FINAIS}

Enfim, Hector Babenco parece deixar evidente que os deslocamentos e as possíveis "transgressões", face da matriz literária, deveram-se a necessidades estéticas e que, no processo de tradução/transposição entre livro e filme, há certamente perdas e ganhos. No que diz respeito às transformações executadas nesse filme, o crítico de cinema Pedro Butcher conclui que, no...

caminho de um livro para um filme, afinal, há sempre perdas. Mas a sensação se dissipa quando se percebe que as imagens de "Carandiru" se recusam a ir embora. Elas persistem, voltam em ocasiões inesperadas, passam a fazer parte da memória. Sinal que o filme é uma obra em si. Enquanto o livro tem importância concreta, sem que tenha feito de Varella um artista, o filme é, inegavelmente, a obra de autor, um sujeito (no sentido amplo) que tem uma história para contar e um ponto de vista sobre ela, identificando-se com a narrativa. (BUTCHER, 2003). 
Portanto, partindo do argumento de que todo filme tem vida própria e, por esse motivo, não exige, necessariamente, leitura prévia do livro que, por ventura, lhe tenha servido de modelo, é preciso encarar as produções cinematográficas, resultantes de matrizes literárias, como leituras possíveis sob a perspectiva peculiar a cada cineasta. E como obra pronta e completa, cada filme pode ser compreendido por si só. Identificar as possíveis interseções entre livro e filme, nesse caso, vai exigir do leitor/espectador hábitos específicos de leitura, a fim de fazer associações e deduções pertinentes, capazes de estabelecer conexões e verificar disjunções entre uma obra e outra, entre essa teia que comporta os dois modos de "ver", a saber, o da literatura e o do cinema.

\section{REFERÊNCIAS BIBLIOGRÁFICAS}

ANDREW, Dudley. Adaptation. In: NAREMORE, James. Film Adaptation. New Jersey: Rutgers, 2000. p. 29-37.

ARNHEIN, Rudolf. A arte no cinema. Trad. Maurice Francis Nunes. Lisboa: Editorial Áster, [1960].

BABENCO, Hector. Notas de produção. In: CARANDIRU (o filme). Direção: Hector Babenco. São Paulo: Globo Filmes. DVD, disco 2, 2003.

BAZIN, André. Por um cinema impuro: defesa da adaptação. In: BAZIN, André. O cinema: ensaios. Trad. Eloísa de Araújo Ribeiro. São Paulo: Brasiliense, 1991.

BUENO, Clóvis. Notas de produção. In: CARANDIRU (o filme). Direção: Hector Babenco. São Paulo: Globo Filmes. DVD, disco 2, 2003.

BUTCHER, Pedro. Carandiru: as memórias do cárcere de Hector Babenco. Folha de São Paulo, 27 mar. 2003.

CAETANO, Daniel (Org.). Cinema brasileiro 1995-2005: ensaios sobre uma década. Rio de Janeiro: Contracampo/Azougue Ed., 2005.

CARANDIRU. Direção: Hector Babenco. Roteiro: Victor Navas, Fernando Bonassi e Hector Babenco. Câmera: Walter Carvalho. 
Montagem: Mauro Alice. Direção de arte: Clóvis Bueno. Música: André Abujamra. Intérpretes: Luiz Carlos Vasconcelos, Milton Gonçalves, Ivan de Almeida, Rodrigo Santoro, Ailton Graça e outros. Realização: São Paulo: Globo Filmes, 2003. Bobina cinematográfica, 2 DVDs (146 min.), son., color.

CARVALHO, Mario Cesar. Carandiru: um filme de Hector Babenco. São Paulo: Wide Publishing, 2003.

COSTA, Fernando Morais da. Se pouco se diz sobre o som, quem fala sobre o silêncio nos filmes? Gragoatá, p. 105-116, 2004.

FERNANDEZ, Alexandre Agabiti. De volta ao cárcere: o cineasta da palavra. Entrevista com Hector Babenco. Culti, n. 68, ano VI, p. 08-15, 2003.

GARDIES, André. Le narrateur sonne toujours deux fois. In: GAUDREAUT, André; GROESTEEN, Thierry (Dir.). La transécriture: pour ume théorie de l'adaptation. Coloque de Cérisy. Québec: Nota Bene, 1992.

GENETTE, Gérard. Palimpsestes. Paris: Seuil, 1982.

GRONEMEYER, Andréa. Film: a Concise History. New York: Laurence King, 1998.

MÁXIMO, João. A música do cinema: os cem primeiros anos. Rio de Janeiro: Rocco, 2003. v. 2.

METZ, Christian. Linguagem e cinema. Trad. Marilda Pereira. São Paulo: Perspectiva, 1980.

MUANIS, Felipe. Justiça aos olhos de quem? Linguagens dos filmes de cárcere. Revista de Comunicação, Cultura e Política, Rio de Janeiro: PUC, Dep. de Comunicação Social, v. 5, n. 10, jan.-jun. 2005.

PIZA, Daniel. Babenco nas celas do horror. O Estado de São Paulo, 23 mar. 2003. Caderno 2.

STAM, Robert. Beyond Fidelity: the Dialogics of Adaptation. In: NAREMORE, James. Film Adaptation. New Jersey: Rutgers, 2000. 
VARELlA, Drauzio. Estação Carandiru. São Paulo: Companhia das Letras, 1999.

VARELLA, Drauzio. Notas de produção. In: CARANDIRU (o filme). Direção: Hector Babenco. São Paulo: Globo Filmes. DVD, disco 2, 2003. 